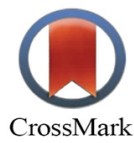

\title{
Collagenous Gastritis, a Rare Cause of Dyspepsia Resistant to Treatment; A Case Report
}

\author{
Farhad Zamani ${ }^{1}$, Amirhossein Boghratian ${ }^{1}$, Ali Zare Mehrjardi ${ }^{1}$, \\ Farshad Naserifar ${ }^{1}$, Jamshid Vafaeimanesh ${ }^{2, *}$
}

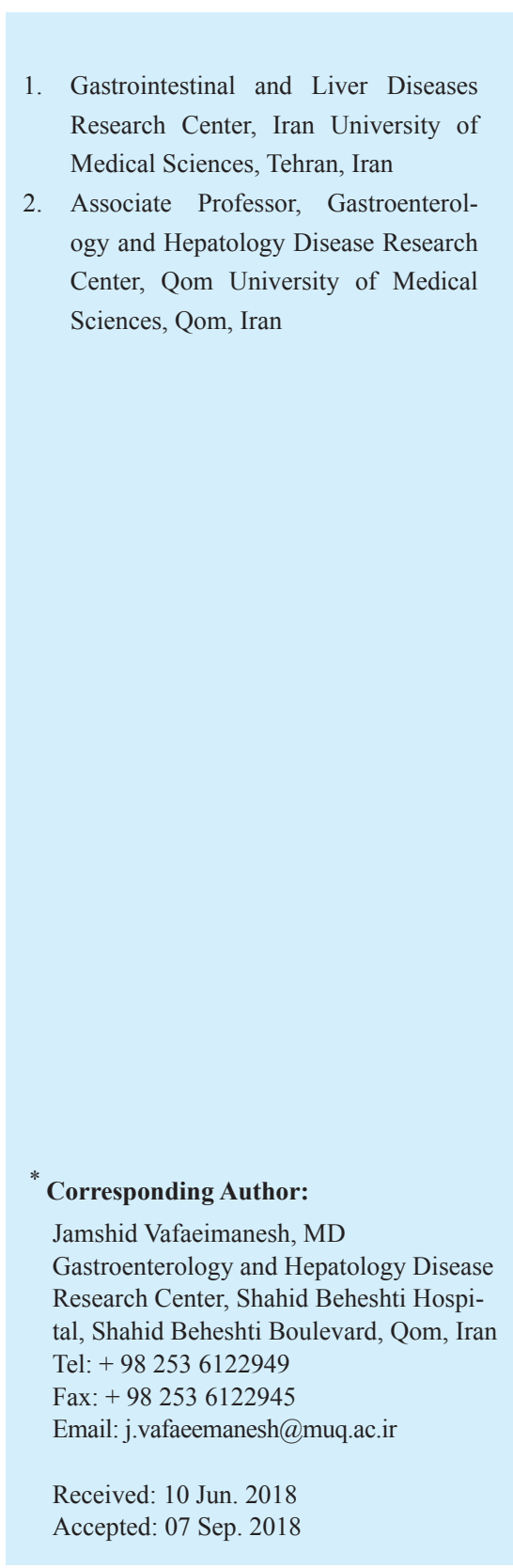

\begin{abstract}
Collagenous gastritis is hardly ever found in children and adults. Based on the extent of collagenous changes in the bowel, various symptoms may develop including iron deficiency, anemia, and abdominal pain in most of the patients.

We present a 30-year-old man with persistent abdominal pain and anemia due to collagenous gastritis.
\end{abstract}

KEYWORDS:

Collagenous gastritis, Abdominal pain, Dyspepsia

Please cite this paper as:

Zamani F, Boghratian AH, Zare Mehrjardi A, Naserifar F, Vafaeimanesh J. Collagenous Gastritis, a Rare Cause of Dyspepsia Resistant to Treatment; A Case Report. Middle East J Dig Dis 2018;10:263-266. doi: 10.15171/mejdd.2018.121.

\section{INTRODUCTION}

Collagenous gastroenteritis includes collagenous gastritis, collagenous sprue, and collagenous colitis. It is a rare disease. Although collagenous colitis has been reported often in this disease category, ${ }^{1,2}$ collagenous gastritis, and collagenous sprue involving the proximal side of the gastrointestinal tract are more uncommon. Studies have confirmed the correlation with autoimmune diseases, especially celiac sprue, but data on the pathogenesis of collagenous gastritis is very scarce. Two phenotypes of the disease, namely pediatric and adult, have been identified according to the case reports so far. ${ }^{3}$ Upper gastrointestinal symptoms, including abdominal pain, and anemia secondary to the stomach-specific inflammation and collagen deposition are the symptoms of the pediatric type. ${ }^{3,4}$ However, in the adult type, collagenous colitis occurs simultaneously, which is believed to be correlated with the autoimmune processes and celiac disease. ${ }^{3}$ In adults, collagenous gastritis without colonic involvement is exceptionally rare. A patient suffering from isolated collagenous gastritis has been described in this report.

\section{CASE REPORT}

A 30-year-old man was referred with a history of chronic intermittent abdominal pain. He had lost weight considerably for about 4 months. According to the physical examination, 


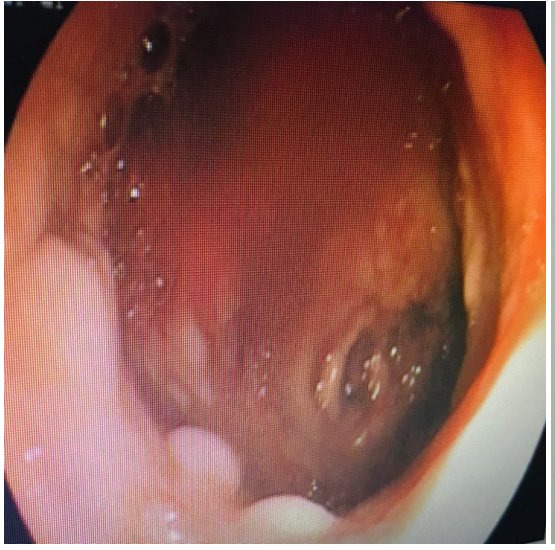

Fig.1: Endoscopy shows the nodular and erythematous appearing gastric mucosa in the gastric wall and antrum.

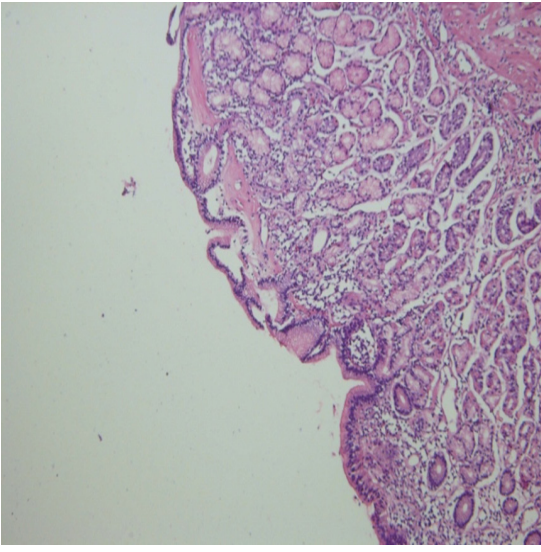

Fig.2: There is marked thickening of subepithelial basement membrane in antral mucosa. (X100, H\&E stain).

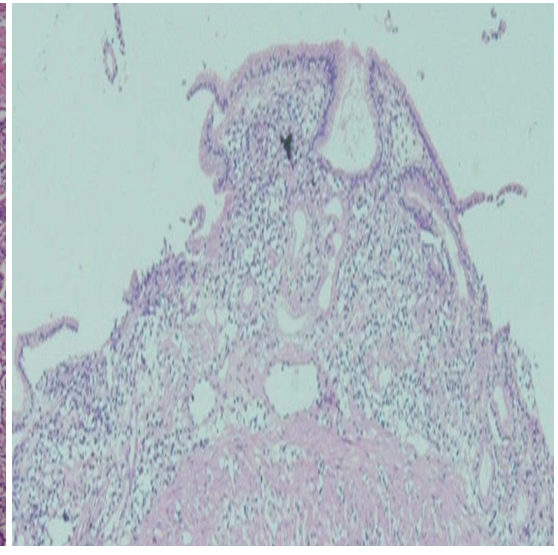

Fig.3: In this area, moderately severe atrophy of glandular component of antrum is evident (x100, H\&E). except for the epigastric tenderness, there was no other point. He was anemic and his hemoglobin level was $9 \mathrm{~g} / \mathrm{dL}$.

He was totally normal in terms of the basic serological tests. His liver tests as well as imaging examinations including abdomen radiography and ultrasonography, celiac serology, thyroid function tests, and pancreatic enzyme tests were normal. Since he has lost weight significantly, an Esophagogastroduodenoscopy (EGD) was subsequently performed. The results showed nodular and erythematous mucosa of the stomach and duodenum (figure 1).

In a histological examination of gastric biopsy samples, no specific finding but chronic gastritis was reported. Colonoscopy was normal. He was prescribed proton pump inhibitors for 3 months. After a 3-month treatment, the patient's abdominal pain slightly improved but continued. Therefore, again upper gastrointestinal endoscopy was performed. The appearance of the endoscopy did not improve and gastric mucosal biopsy showed marked thickening of sub-epithelial basement membrane in antral mucosa (X100, H\&E stain, figure 2) and moderately severe atrophy of glandular component of antrum (x100, H\&E, figure 3). He was diagnosed as having collagenous gastritis. An autoimmune evaluation was not positive.

\section{DISCUSSION}

One of the uncommon forms of gastritis is collagenous gastritis. It is characterized in terms of histology by the presence of $>10 \mu \mathrm{m}$ thickness of sub-epithelial surface collagen deposition accompanied by inflammatory infiltrate in the lamina propria. Colletti and colleagues firstly discovered this condition in a 15 -year-old girl in 1989. 5,6 The patient was suffering from recurrent abdominal pain and gastrointestinal bleeding.

Two phenotypes of the disease, namely pediatric and adult, have been identified according to the case reports. The clinical presentations of the disease have been documented for 38 patients; half of these individuals experienced more than one significant sign or symptom. Abdominal pain (57\%), anemia (39\%), nausea/vomiting (26\%), and a documented gastrointestinal bleeding with hematemesis or melena $(22 \%)$ have been reported in adolescents and children. The most common symptom in adults is anemia (67\%), followed by diarrhea $(27 \%)$, and abdominal pain (27\%).

Studies show that collagenous gastritis in adult population is accompanied by autoimmune diseases including Sjögren syndrome, ${ }^{7}$ lymphocytic gastritis, lymphocytic colitis, and ulcerative colitis. According to investigations, the pediatric-type disease has not been transformed into adult-type among the case reports yet. ${ }^{8}$ Collagenous gastritis is usually diagnosed with the histological data on gastric biopsies, which show thick collagenous bands within the sub-epithelium of the gastric mucosa along with an inflammatory infiltrate. It has also been identified with trichrome stain. No standard therapy has been recommended for collagenous gastritis due to the unknown etiology and limited number of the patients. 
Some researchers have used anti-secretory agents including proton pump inhibitors, $\mathrm{H}_{2}$-receptor antagonists, steroids, iron supplementation, and hypoallergenic diets, but the results were not satisfactory enough. Other treatment modalities including sucralfate, mesalazine, bismuth subsalicylate, furazolidone, sulfasalazine, azathioprine, and parenteral nutrition have also been recommended. ${ }^{9}$ Bajwa argues that a gluten-free diet alleviates the symptoms rapidly and sustainably. ${ }^{10}$ According to Vakiani and colleagues ${ }^{11}$ and Rustagi and co-workers, ${ }^{12}$ treating patients with steroids and budesonide for 1.5 years, and oral iron supplementation and a proton pump inhibitor for 0.83 years improved the inflammation, however, it led to unchanged or thicker collagen deposits. They recommended that the treatment could control the inflammation, but as the inflammation progressed, the collagen deposits were unchanged or become thicker. There is not enough data on the natural history of collagenous gastritis. Most of the adult patients are identified by a chronic intermittent course having no significant mortality risk or severe progression. And colorectal cancer or chronic inflammatory bowel disease have not been reported in any of such patients. No evidence has been found on the relationship between collagenous gastritis and any malignant lymphoma or any other gastric disorders. ${ }^{13}$ In another study by Kamimura and colleagues, ${ }^{14}$ a patient was investigated for 14 years. They found that nodular appearance on endoscopy became more conspicuous and developed throughout the stomach. Histological data confirmed the increased thickness of collagen deposits over the 14 years. ${ }^{14}$ Nevertheless, no standard therapy has been recommended for collagenous gastritis due to the unknown etiology and limited number of the patients. More cases are necessary to understand the nature of this disease clearly and recommend a standard therapeutic procedure.

\section{CONCLUSION}

Collagenous gastritis is a rare cause of dyspepsia. Which is far from the mind, but in cases where dyspepsia does not respond to early therapies, more rare diagnoses, including this disease, should be considered.

\section{Funding Sources}

None

\section{Authors Contributions}

All authors have been involved actively and substantially in compiling the present study and they take the responsibility for this research collectively.

\section{ETHICAL APPROVAL}

There is nothing to be declared.

\section{CONFLICT OF INTEREST}

The authors declare no conflict of interest related to this work.

\section{REFERENCES}

1. Freeman HJ. Complications of collagenous colitis. World J Gastroenterol 2008;14:1643-5 doi:10.3748/ wjg.14.1643.

2. Camarero C, Leon F, Colino E, Redondo C, Alonso $\mathrm{M}$, Gonzalez C, et al. Collagenous colitis in children: clinicopathologic, microbiologic, and immunologic features. J Pediatr Gastroenterol Nutr 2003;37:50813. doi:10.1097/0000517 6-200310000-00020.

3. Lagorce-Pages C, Fabiani B, Bouvier R, Scoazec JY, Durand L, Flejou JF. Collagenous gastritis: a report of six cases. Am J Surg Pathol 2001;25:1174-9. doi: 10.1097/0000 0478-200109000-00008.

4. Hijaz NM, Septer SS, Degaetano J, Attard TM. Clinical outcome of pediatric collagenous gastritis: case series and review of literature. World J Gastroenterol 2013;19:1478-84. doi:10.3748/wjg.v19.i9.1478.

5. Colletti RB, Trainer TD. Collagenous gastritis. Gastroenterology 1989;97:1552-5.

6. Winslow JL, Trainer TD, Colletti RB. Collagenous gastritis: a long-term follow-up with the development of endocrine cell hyperplasia, intestinal metaplasia, and epithelial changes indeterminate for dysplasia. Am J Clin Pathol 2001;116:753-8. doi: 10.1309/3WM2-THU3-3Q2A-DP47.

7. Stancu M, De Petris G, Palumbo TP, Lev R. Collagenous gastritis associated with lymphocytic gastritis and celiac disease. Arch Pathol Lab Med 2001;125:157984. doi:10.1043/0003-9985(2001)125<1579:CGAW $\mathrm{LG}>2.0 . \mathrm{CO} ; 2$.

8. Arnason T, Brown IS, Goldsmith JD, Anderson W, O'Brien BH, Wilson C, et al. Collagenous gastritis: a morphologic and immunohistochemical study of 40 patients. Mod Pathol 2015;28:533-44. doi:10.1038/ modpathol.2014.119.

9. Kamimura K, Kobayashi M, Sato Y, Aoyagi Y, Terai S. Collagenous gastritis: Review. World $J$ Gastrointest Endosc 2015;7:265-73. doi:10.4253/wjge. v7.i3.265. 
10. Bajwa RU, Joshi A, Heikenen JB. Successful Treatment of Collagenous Gastritis in a Child With a Gluten-Free Diet. WMJ 2015;114:271-3.

11. Vakiani E, Arguelles-Grande C, Mansukhani MM, Lewis SK, Rotterdam H, Green PH, et al. Collagenous sprue is not always associated with dismal outcomes: a clinicopathological study of 19 patients. Mod Pathol 2010;23:12-26. doi:10.1038/modpathol.2009.151.

12. Rustagi T, Rai M, Scholes JV. Collagenous gastroduodenitis. J Clin Gastroenterol 2011;45:794-9. doi: 10.1097/MCG.0b013e31820c6018.

13. Bonderup OK, Folkersen BH, Gjersoe P, Teglbjaerg PS. Collagenous colitis: a long-term follow-up study. Eur J Gastroenterol Hepatol 1999;11:493-5. doi:10.1097/00042737-199905000-00005.

14. Kamimura K, Kobayashi M, Narisawa R, Watanabe $\mathrm{H}$, Sato Y, Honma T, et al. Collagenous gastritis: endoscopic and pathologic evaluation of the nodularity of gastric mucosa. Dig Dis Sci 2007;52:995-1000. doi:10.1007/s10620-006-9278-y. 